\title{
A new classification of cross-sectional root canal shape changes, a cone-beam computed tomography study
}

\section{Svetlana Razumova}

Rossijskij universitet druzby narodov Medicinskij institut

\section{Anzhela Brago}

Rossijskij universitet druzby narodov Medicinskij institut

Haydar Barakat ( $\nabla$ dr.haydarbarakat@yahoo.com )

Rossijskij universitet druzby narodov Medicinskij institut https://orcid.org/0000-0003-0911-3063

Ammar Howijieh

Rossijskij universitet druzby narodov Medicinskij institut

\section{Yuliya Kozlova}

Rossijskij universitet druzby narodov Medicinskij institut

\section{Malina Baykulova}

Rossijskij universitet druzby narodov Medicinskij institut

\section{Research article}

Keywords: classification, cross-sectional shape, endodontic treatment, root canal

Posted Date: June 1st, 2020

DOl: https://doi.org/10.21203/rs.3.rs-31625/v1

License: (9) (i) This work is licensed under a Creative Commons Attribution 4.0 International License. Read Full License 


\section{Abstract}

Background: The root canal system is considering the most important factor in endodontic treatment, due to the complexity of its anatomy and morphology. The aim of this study was to present a new classification of root canal shape changes in three thirds (coronal, middle, apical) in different age groups using cone-beam computed tomography scanning.

Materials and methods: 300 CBCT scans for patient aged 20-70 were evaluated to study the morphology of the cross-sectional root canal shape in coronal, middle and apical thirds among three age groups; young (20-44), middle (45-59) and elderly (60-70). The root canal shape was classified as follow: round, oval, ribbon.

Results: The cross-sectional root canal shape was identified in two groups: canals with an unchanging (constant) shape and canals with changing shape. In turn, in canals with changing shape, the change could be identified in the region of the middle or apical thirds of the canal. The results showed that root canal shape changes in two cases: 1 ) the presence of one or more canals in the root (with or without isthmus between them), 2) with age, as it was observed that the cross-sectional shape of the root canal becomes round in the apical third with age.

Conclusion: A new classification of the changes of root canal shape in three thirds (coronal, middle, apical) was presented in this study.

\section{Introduction}

The root canal system is considering the most important factor in endodontic treatment, due to the complexity of its anatomy and morphology. This system varies among populations even in individuals in the same population, the variations in root canal morphology are still a major issue for endodontists [1, 2]. The significant knowledge of root canal morphology and its variations is a basic requirement for successful endodontic treatment. Knowing the root canal system means to know the number of roots and canals, the canals configuration and cross-sectional shape.

The variations in the geometry of the cross-sectional root canal shape before forming and cleaning have a great influence on the changes that occur during root canal preparation and depend on the preparation methods. The preparation and treatment of the apical third of the root canal and apical foramen has been the subject of numerous studies [3-5].

The root canals could have various cross-sectional shapes, including round, oval, long oval, ribbon ones or C-shaped $[6,7]$. In the literature, the authors have defined the canal shapes in the coronal third of the root canal, as round, oval, round oval, ribbon and C-shaped canals [8-10]. The most common classification of ribbon canals (that contain isthmus between the canals) was defined by many authors such as Kim \& Hsu [11], Kim \& Peroca [12] and Teixeira [13]. Several researchers analyzed the presence of isthmus between canals especially in the molar region [14-17]. Some authors have defined the ribbon 
shapes (with or without isthmus) in the apical third and it was observed that the root canal shape in the apical third could differ from the other thirds.

Recent technologies such as using high-resolution, non-invasive, three-dimensional, cone -beam computed tomography (CBCT) allows to study the morphology of root canal shape precisely [18].

The aim of this study was to present a new classification of root canal shape changes in three thirds (coronal, middle, apical) in different age groups using cone-beam computed tomography scanning.

\section{Materials And Methods}

Three hundred CBCT scans for 300 hundred subjects, aged (20-70) years, were included in this study. The subjects were divided into three age groups by 100 subjects for each: young age (20-44) years, middle age (45-59) years and elderly (60-70). A written consent was obtained from the subjects participating in the study. The study was conducted in accordance with the Helsinki Declaration of 1975, as revised in 2000, and was approved by the ethical committee of the Peoples' Friendship University of Russia University (Protocol 6 at 21.02.2019). The study was conducted in radiologic diagnostic center for three-dimensional radiological scanning in Moscow.

The CBCT scans were taken using a 3D eXam (KaVo, Biberach, Germany) with standard exposure settings ( $23 \mathrm{~cm} \times 17 \mathrm{~cm}$ field of view, $0.3 \mathrm{~mm}$ voxel size, $110 \mathrm{kv}, 1.6-20 \mathrm{~s}$ ) and were viewed by three examiners in a semi-dark room using I-CAT viewer software (version 10, Hatfield, England).

The morphology of the cross-sectional root canal shape was studied on healthy teeth in axial slices in three thirds (coronal, middle, apical) in each age group. For maxillary teeth: 378 Central incisors, 392 Lateral incisors, 357 Canines, 310 First premolars, 300 Second Premolars, 261 First molars and 250 Second molars were studied. For mandibular teeth: 481 Central incisors, 475 Lateral incisors, 456 Canines, 347 First premolars, 300 Second Premolars, 250 First molars and 248 Second molars were studied.

The root canal shape was recorded according to this classification: round, oval, long oval and ribbon.

The criteria for root canal shape classification was taken as follow: the round canal was defined when the mesio-distal diameter of the root canal was equal to the bucco-lingual/palatal diameter. The oval and long oval canals were determined when the bucco-lingual/palatal diameter was two to four time greater than the mesio-distal diameter of the root canal. The ribbon canal shape (that contain isthmus) was studied according to Kim's Classification [12] as follow:

Type I: Incomplete isthmus between two canals.

Type II: A complete isthmus between two canals.

Type III: A short, complete isthmus between two canals. 
Type IV: A complete or incomplete isthmus between three or more canals.

Type V: two or three canals without obvious connection between them.

The changes in root canal shape was recorded in coronal and middle and apical thirds of the root canal system.

\section{Statistical analysis}

IBM SPSS Statistics v 22.0 licensed package (IBM, Chicago, IL, USA) was used for statistical processing of the study data. The method of descriptive statistics was used for statistical processing of the received data.

\section{Results}

The cross-sectional root canal shape was identified in two groups: canals with an unchanging (constant) shape and canals with changing shape. In turn, in canals with changing shape, the change could be identified in the region of the middle or apical thirds of the canal. (Table 1)

Table 1

classification of cross-sectional root canal shape according to teeth

\begin{tabular}{|c|c|c|c|}
\hline \multirow[t]{3}{*}{ No change } & \multicolumn{3}{|c|}{ Cross-sectional root canal shape } \\
\hline & \multicolumn{3}{|l|}{ Change } \\
\hline & $\begin{array}{l}\text { In the middle } \\
\text { third }\end{array}$ & In the apical third & In the middle \& apical thirds \\
\hline Anterior teeth & $\begin{array}{l}\text { Mandibular } \\
\text { incisors }\end{array}$ & $\begin{array}{l}\text { mandibular premolars \& } \\
\text { One-rooted maxillary } \\
\text { premolars }\end{array}$ & $\begin{array}{l}\text { mandibular premolars \& } \\
\text { One-rooted maxillary } \\
\text { premolars }\end{array}$ \\
\hline $\begin{array}{l}\text { Two-rooted } \\
\text { maxillary premolars }\end{array}$ & $\begin{array}{l}\text { One-rooted } \\
\text { maxillary } \\
\text { premolars }\end{array}$ & $\begin{array}{l}\text { Mesio-buccal canals } \\
\text { maxillary molars }\end{array}$ & $\begin{array}{l}\text { Mesio-buccal canals } \\
\text { maxillary molars }\end{array}$ \\
\hline $\begin{array}{l}\text { Distal and palatal } \\
\text { canals maxillary } \\
\text { molars }\end{array}$ & $\begin{array}{l}\text { Mandibular } \\
\text { premolars }\end{array}$ & $\begin{array}{l}\text { Mesial and distal canals } \\
\text { mandibular molars }\end{array}$ & $\begin{array}{l}\text { Mesial and distal canals } \\
\text { mandibular molars }\end{array}$ \\
\hline
\end{tabular}

According to the obtained results, this study suggested a new classification of the changes in crosssectional root canal shape in coronal, middle and apical thirds, defined in table 2. 
Table 2

Three-thirds classification of cross-sectional root canal shape

\section{Types Description}

Type I Un-changed cross-sectional root canal shape from coronal to apical third

Type II Changed cross-sectional root canal shape in the middle third

Type III Changed cross-sectional root canal shape in the middle and apical thirds

Type IV Changed cross-sectional root canal shape in the apical third

\section{Anterior teeth}

For maxillary anterior teeth: the cross-sectional root canal shape was defined to be round for incisors and oval for canines in the three thirds in each age group. No statistical differences were observed for this group of teeth. (Figure 1) the significant difference was observed in the diameter of the root canal in elderly group which was observed to be smaller than other age groups $(P<0.05)$.

For mandibular anterior teeth: the cross-sectional root canal shape was defined to be oval or long oval for incisors in the three thirds in $95 \%$ at the young age. In $5 \%$ the cross-sectional root canal shape was changed in the middle third to ribbon type I and in the apex re-changed to long-oval. For canines, the shape of the root canal was defined to be oval in three thirds in $96 \%$. In $4 \%$ the root canal shape changed in the middle third. (Figure 2)

\section{Premolars teeth}

For two-rooted maxillary premolars, the root canal shape was round in the three thirds in each root in each age group. For one-rooted maxillary and mandibular premolars, it was observed changes in root canal shape in coronal, middle and apical layers. In some cases, the shape changed from oval or round to ribbon or from oval to round in the apical third. (Figures 3 ) The changes were observed more in the middle and apical third of the premolars in each age groups.

\section{Molars teeth}

For maxillary molars, the following regularity of root canals shape was established as follow: the palatal and distobuccal canals usually have a round or oval shape that didn't change in the three thirds in most cases. The mesiobuccal canals had a variable structure: the cross-sectional shape could change from oval in the coronal third to ribbon especially in the apical third. (Figure 4)

For mandibular molars, it was observed a variability in the cross-sectional root canals shape for both the distal and mesial roots. 
More often the shape changed in the young and middle age group. For the elderly age group, the unchanging shape of the canals in the mesial and distal roots was most characteristic. (Figure 5)

Tables 3, 4, 5 represent the new classification of cross-sectional root canal shape changes among age groups.

Table 3

Changes of cross-sectional root canal shape in young age group

\begin{tabular}{|llllll|}
\hline Young group & Root & Type I & Type II & Type III & Type IV \\
\hline Maxillary anterior teeth & One-rooted & $100 \%$ & 0 & 0 & 0 \\
\hline Maxillary premolars & Two-rooted & $100 \%$ & 0 & 0 & 0 \\
\cline { 2 - 5 } & One-rooted & $60 \%$ & $13 \%$ & $17 \%$ & $10 \%$ \\
\hline Maxillary molars & MB & $5 \%$ & $6 \%$ & $49 \%$ & $40 \%$ \\
\cline { 2 - 3 } & DB & $75 \%$ & 0 & $15 \%$ & $10 \%$ \\
\hline Mandibular anterior teeth & One-rooted & $95 \%$ & $5 \%$ & 0 & 0 \\
\hline Mandibular premolars & One-rooted & $36 \%$ & $8 \%$ & $40 \%$ & $16 \%$ \\
\hline Mandibular molars & M & $68 \%$ & 0 & $12 \%$ & $20 \%$ \\
\cline { 2 - 5 } & D & $46 \%$ & 0 & $28 \%$ & $26 \%$ \\
\hline
\end{tabular}


Table 4

Changes of cross-sectional root canal shape in middle age group

\begin{tabular}{|llllll|}
\hline Middle group & Root & Type I & Type II & Type III & Type IV \\
\hline Maxillary anterior teeth & One-rooted & $100 \%$ & 0 & 0 & 0 \\
\hline Maxillary premolars & Two-rooted & $100 \%$ & 0 & 0 & 0 \\
\cline { 2 - 6 } & One-rooted & $49 \%$ & $4 \%$ & $34 \%$ & $13 \%$ \\
\hline Maxillary molars & MB & $3 \%$ & $10 \%$ & $46 \%$ & $41 \%$ \\
\cline { 2 - 6 } & DB & $71 \%$ & 0 & $11 \%$ & $18 \%$ \\
\hline Mandibular anterior teeth & One-rooted & $96 \%$ & $3 \%$ & $1 \%$ & 0 \\
\hline Mandibular premolars & One-rooted & $53 \%$ & $2 \%$ & $31 \%$ & $14 \%$ \\
\hline Mandibular molars & M & $58 \%$ & 0 & $24 \%$ & $18 \%$ \\
\cline { 2 - 6 } & D & $60 \%$ & 0 & $12 \%$ & $28 \%$ \\
\hline
\end{tabular}

Table 5

Changes of cross-sectional root canal shape in elderly age group

\begin{tabular}{|llllll|}
\hline Elderly group & Root & Type I & Type II & Type III & Type IV \\
\hline Maxillary anterior teeth & One-rooted & $100 \%$ & 0 & 0 & 0 \\
\hline Maxillary premolars & Two-rooted & $100 \%$ & 0 & 0 & 0 \\
\cline { 2 - 6 } & One-rooted & $56 \%$ & $9 \%$ & $24 \%$ & $11 \%$ \\
\hline Maxillary molars & MB & $6 \%$ & $7 \%$ & $39 \%$ & $48 \%$ \\
\cline { 2 - 6 } & DB & $76 \%$ & 0 & $9 \%$ & $15 \%$ \\
\hline Mandibular anterior teeth & One-rooted & $93 \%$ & $5 \%$ & $2 \%$ & 0 \\
\hline Mandibular premolars & One-rooted & $43 \%$ & $5 \%$ & $24 \%$ & $28 \%$ \\
\hline Mandibular molars & M & $64 \%$ & 0 & $21 \%$ & $15 \%$ \\
\cline { 2 - 6 } & D & $56 \%$ & 0 & $31 \%$ & $13 \%$ \\
\hline
\end{tabular}

When comparing the cross-sectional root canal shape changes among the study age groups, it was observed a significant difference in premolar and molar teeth in middle and elderly group. $(P<0.05)$ 


\section{Discussion}

The cross-sectional root canal shape varies, it could be round, oval, long oval or ribbon. This was the first study to analyze the cross-sectional root canal shape and its changes in coronal, middle and apical thirds among different age groups. This study has demonstrated the changes in the root canal cross-sectional shape between the coronal, middle and apical thirds among different age groups. The results of this study showed that root canal shape changes in two cases: 1 ) the presence of one or more canals in the root (with or without isthmus between them), 2) with age, as it was observed that the cross-sectional shape of the root canal becomes round with age in the apical third. This study described four types of root canal shape changes as follow: type l: un-changed cross-sectional root canal shape from coronal to apical third; type II: changed cross-sectional root canal shape in the middle third; type III: changed crosssectional root canal shape in the middle and apical thirds; type IV: changed cross-sectional root canal shape in the apical third. This is the main difference of our classification from other classifications, which consider the cross section at only one level, or describe the unchanging shape of the canal along its entire length.

It is known that non-round canals can't be enlarged to round without perforation which weakens the root. The presence of different variants of root canal morphology require different methods of preparation and obturation. The preparation of oval and ribbon canals cannot be prepared to a round shape created by rotating tools, and therefore, they remain unprepared, which could potentially lead to failure of endodontic treatment. The requirements for the preparation of the conical shape of the root canal include requirements for irrigation, evacuation of debris and subsequent obturation. But if the taper of the tool used for cleaning and shaping the channel does not match the taper of the canal, the purpose of the mechanical preparation will not be achieved. If the instrument has excessive taper, this will lead to excessive removal of the coronal dentin and weakening of the tooth structure, and at that time, the instrument will not be able to effectively clean the apical third of the canal.

Mechanical preparation of the root canals can be performed using hand tools or rotary instruments where the canals are formed by rotation or reciprocal movement. Whether the entire wall of the main canal will be properly cleaned and shaped accordingly depends on a number of factors, such as canal morphology, canal wall thickness, canal taper, type of tool used and its size. Among all factors, the root canal morphology can be considered the most important, since all other factors - the choice of preparation technique and the choice of instrument depend on and are determined by the shape of the canal. It is very difficult to adequately clean the canals only with tools, which increases the importance of choosing the right solution for irrigation with a sufficient volume and method of irrigation. Most often used tools create a round canal shape, leaving isthmuses, narrowing unprepared and filled with a greased layer and debris. Ultrasound activation of irrigation can better clean lateral and additional canals [5].

Mehrvarzfar et al. studied the ribbon shape in the apical third according to Kim \& Peroca classification in the mesial roots of mandibular molars, it was observed at $6 \mathrm{~mm}$ of the apex type I in $8.3 \%$, type II $40 \%$, type III $8.3 \%$, type IV $18.3 \%$ and type V $25 \%$. At $4 \mathrm{~mm}$ of the apex the prevalence of types I, II, III, IV and V 
was $11.7 \%, 16.7 \%, 15 \%, 10 \%$ and $46.8 \%$, respectively, and at $2 \mathrm{~mm}$ of the apex the prevalence of types III, III, IV and V was as follow $30 \%, 10 \%, 5 \%, 3.3 \%$ and $51.7 \%$, respectively [9]. This study demonstrates the change of root canal shape in the apical third which coincide with the results of our study.

In Brazil a micro-CT study of Fumes et al. was conducted to study the shape of the canals of the first and second molars in the apical area. For mandibular first molars; a rounded shape was detected in the mesial root in $30 \%$, oval in $10 \%$, ribbon in $50 \%$ and irregular in $10 \%$ of cases, and in the distal root a round shape in $30 \%$, oval in $20 \%$, ribbon in $40 \%$ and irregular in $10 \%$ of cases. For the mandibular second molars in the mesial root revealed a round shape in $30 \%$, ribbon in $60 \%$ and irregular in $10 \%$ of cases, and in the distal root a round shape in $40 \%$, oval in $20 \%$ and ribbon in $40 \%$ of cases. For maxillary first molar, a round shape in $10 \%$, oval in $30 \%$, ribbon in $50 \%$ and irregular in $10 \%$ of cases were revealed in the mesio-buccal root, for the disto-buccal root, an oval shape was observed in $100 \%$ of cases, and in the palatal root round shape was found in $20 \%$ and oval in $80 \%$ of cases. for the maxillary second molars in the mesio-buccal root revealed a rounded shape in $20 \%$, oval in $30 \%$, ribbon in $40 \%$ and irregular in $10 \%$ of cases, in the disto-buccal root revealed an oval shape in $100 \%$ of cases, and in the palatal root a rounded shape in $30 \%$, oval in $70 \%$ of cases [19].

In 2016 (China), Hu et al. [20] studied morphological changes in the root canals of the maxillary first premolar using СВCT in different age groups and found that the morphology of the sections in most age groups was ribbon (48.5\%) and oval (28.2\%). In 2019 the researchers [21] studied the anatomy and morphology of the second maxillary premolar using CBCT and differences with age, and found that in most groups, the ribbon shape was higher in $57.8 \%$ of cases and the oval form in $31.3 \%$. Researchers concluded that with age, the percentage of the round shape gradually increased, while the ribbon and oval shapes decreased, these results are in agreeable with the results of this study.

Kacharaju et al. studied the morphology of the root canals of mandibular premolars in the Malaysian population. The study revealed that in the coronal third, an oval shape was detected in $52 \%$, round in $1 \%$ and irregular in $46 \%$. In the middle third of the canal, the oval shape was detected in $36 \%$ of cases, round in $21 \%$ of cases, irregular in $30 \%$ of cases, ribbon with isthmus in $7 \%$ of cases, and ribbon without isthmus in $6 \%$ of cases. In the apical third, the canal shape changed; in $22 \%$ an oval shape was detected, in $37 \%$ it was round, in $25 \%$ it was irregular, in $8 \%$ it was ribbon with an isthmus and in $8 \%$ it was ribbon without an isthmus [8].

This variability of the root canal shape is important to understand in order to complete the endodontic treatment stage-mechanical treatment (preparation of the root canal). The choice of instrument and technique for preparing the canal will determine the effectiveness and correctness of this stage, and therefore a favorable prognosis of treatment.

According to the presented classification, the most changes were observed in the middle and apical thirds of the root canal in each age group. 


\section{Conclusion}

Within the limits of this study, the results showed that the cross-sectional root canal shape varies in different thirds of the root canal and among age groups, these variations was presented in a new classification explained the changes in root canal shape in the three thirds. These variations should be taken into consideration while performing endodontic treatment to choose the right technique for cleaning and shaping.

\section{Abbreviations}

- CBCT - Cone-Beam computed Tomography

- MB-Mesio-Buccal

- DB-Disto-Buccal

- M-Mesial

- D-Distal

\section{Declarations}

\section{Ethics approval and consent to participate:}

The study was conducted in accordance with the Helsinki Declaration of 1975, as revised in 2000, and was approved by the ethical committee of the Peoples' Friendship University of Russia University (Protocol 6 at 21.02.2019). A written consent was obtained from the subjects participating in the study

\section{Consent for publication:}

Not applicable

\section{Availability of data and materials:}

The datasets used and/or analysed during the current study are available from the corresponding author on reasonable request.

\section{Competing interests:}

The authors declare that they have no competing interests

\section{Funding:}




\section{Authors' contributions:}

SR: Conceptualization, Methodology, Software. AB: Data curation, Writing- Original draft preparation. HB, AM: Visualization, Investigation. YK: Supervision. MB: Software, Validation. SR, HR, AM: WritingReviewing and Editing.

\section{Acknowledgements:}

Not applicable

\section{References}

1. Razumova S, Brago A, Khaskhanova L, Howijieh A, Barakat H, Manvelyan A. A Cone-Beam Computed Tomography Scanning of the Root Canal System of Permanent Teeth among the Moscow Population. Int J Dent. 2018;2018:2615746. Published 2018 Sep 25. doi:10.1155/2018/2615746

2. Boschetti E, Silva-Sousa YTC, Mazzi-Chaves JF, Leoni GB, Versiani MA, Pecora JD, et al. Micro-CT Evaluation of Root and Canal Morphology of Mandibular First Premolars with Radicular Grooves. Braz Dent J. 2017;28(5):597-603. doi: 10.1590/0103-6440201601784

3. Peters $\mathrm{OA}$, Peters $\mathrm{Cl}$, Schönenberger $\mathrm{K}$, Barbakow F. ProTaper rotary root canal preparation: effects of canal anatomy on final shape analysed by micro CT. Int Endod J. 2003;36(2):86-92. https://doi.org/10.1046/j.1365-2591.2003.00626.x

4. Lacerda MF, Marceliano-Alves MF, Pérez AR, Provenzano JC. Cleaning and shaping oval canals with 3 instrumentation systems: a correlative micro-computed tomographic and histologic study. $\mathrm{J}$ Endod. 2017;43(11):1878-84. https://doi.org/10.1016/j.joen.2017.06.032

5. Sousa-Neto MD, Silva-Sousa YC, Mazzi-Chaves JF, Teodoro Carvalho KK. Root canal preparation using micro-computed tomography analysis: a literature review. Braz Oral Res. 2018;32(1):e66. doi: 10.1590/1807-3107bor-2018.vol32.0066.

6. Wu MK, R'oris A, Barkis D, Wesselink PR. Prevalence and extent of long oval canals in the apical third. Oral Surg Oral Med Oral Pathol Oral Radiol Endod. 2000;89:739-43.

7. Jou YT, Karabuchak B, Levin J, Liu D. Endodontic working width: current concepts and techniques. Dent Clin North Am. 2004;48:323-35.

8. Kacharaju KR, Hari P, Yee A, Ngo J, Ismail MF. Analysis of Mandibular Premolars Root Canal Morphology Using Radiographic and Cross-Sectional Techniques in Malaysian Population. Dent Hypotheses. 2019;10:14-9

9. Mehrvarzfar P, Akhlagi NM, Khodaei F, Shojaee G, Shirazi S. Evaluation of isthmus prevalence, location, and types in mesial roots of mandibular molars in the Iranian Population. Dent Res J 
(Isfahan). 2014;11(2):251-256.

10. Martins JN, Mata A, Marques D, Anderson C. Prevalence and Characteristics of the Maxillary Cshaped Molar. J Endod. 2016;42(3):383-9. doi: 10.1016/j.joen.2015.12.013.

11. Hsu Y, Kim S. The resected root surface: the issue of canal isthmuses. Dent Clin N Am. 1997:3:529540.

12. Kim S, Pecora G, Rubinstein R. Color Atlas of Microsurgery in Endodontics. WB Saunders: Philadelphia (USA); 2001.

13. Teixeira FB, Sano CL, Gomes BP, Zaia AA. A preliminary in vitro study of the incidence and position of the root canal isthmus in maxillary and mandibular first molars. Int Endod J. 2003;36:276-80.

14. Mohammadzadeh-Akhlaghi N, Mehrvarzfar P, Hossein M, Dds Z. Incidence, location, and type of isthmus in mandibular second molars among individuals of an Iranian population. J Oral Health Oral Epidemiol. 2018;7(2):59-63.

15. Shrestha S, Karki S, Agrawal N, Vikram M. Prevalence of Different Types of Apical Root Canal Morphology and their Treatment Recommendations in an Institute. J Nepal Med Assoc. 2018;56(210):616-20.

16. Pécora JD, Estrela C, Bueno MR, Porto OC, Alencar AH, Sousa-Neto M, et al. Detection of Root Canal Isthmuses in Molars by Map-Reading Dynamic using CBCT images. Braz Dent J. 2013;24(6):56974. doi: 10.1590/0103-6440201302380.

17. Uma $\mathrm{CH}$, Ramachandran S, Indira R, Shankar P. Canal and isthmus morphology in mandibular incisors-An in vitro study. Endodontology. 2004;16:7-11.

18. Zhu LN, Qian WH, Hong J. A cone-beam computed tomography study of changes in canal isthmus of maxillary first premolars before and after instrumentation. Shanghai Kou Qiang Yi Xue. 2013;22:4145.

19. Fumes AC, Sousa-Neto MD, Leoni GB, Versiani M. Root canal morphology of primary molars: a microcomputed tomography study. Eur Arch Paediatr Dent. 2014;15(5):317-26.

20. Hu RC, Cao LL, Xie W, Hu YQ. Aging changes of the root canal morphology in maxillary first premolars observed by cone-beam computerized tomography. Zhonghua Kou Qiang Yi Xue Za Zhi. 2016;51(4):224-9. doi: 10.3760/cma.j.issn.1002-0098.2016.04.008.

21. Hu RC, Xie W, Hu YQ, Piao ZG. Root canal anatomy of maxillary second premolars at various ages observed by cone-beam CT. Zhonghua Kou Qiang Yi Xue Za Zhi. 2019;54(11):733-738. doi: 10.3760/cma.j.issn.1002-0098.2019.11.003.

\section{Figures}



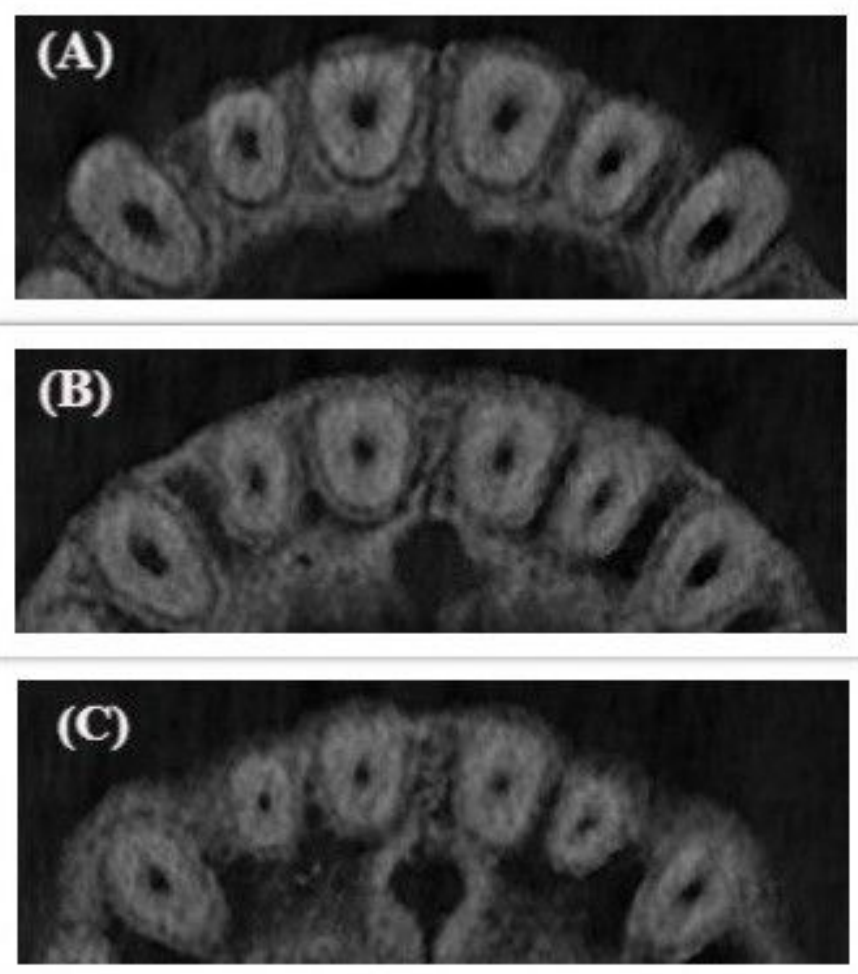

Figure 1

unchanged cross-sectional root canal shape for maxillary anterior teeth (A: Coronal, B: Middle, C: Apical)
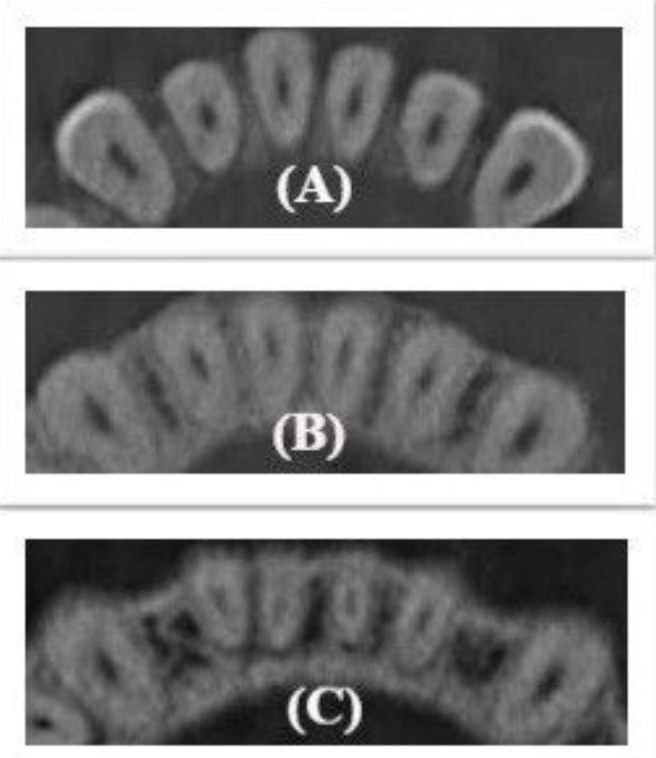

Figure 2

Changed cross-sectional root canal shape for mandibular anterior teeth in the middle third 

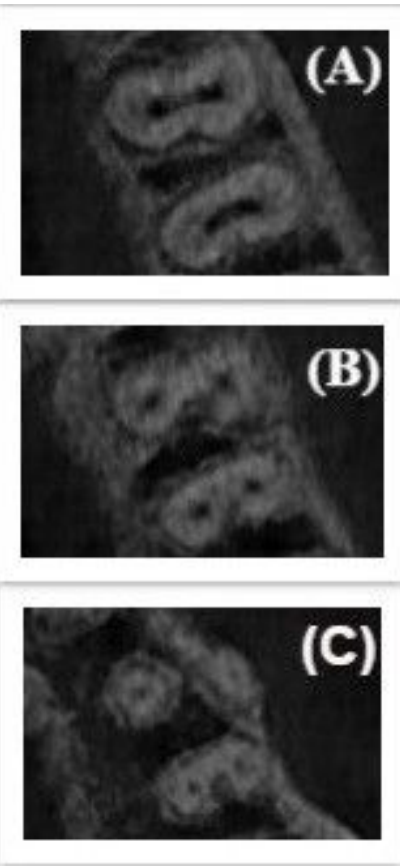

Figure 3

changed cross-sectional root canal shape for maxillary second premolar from oval in the coronal third to ribbon in the middle and apical third

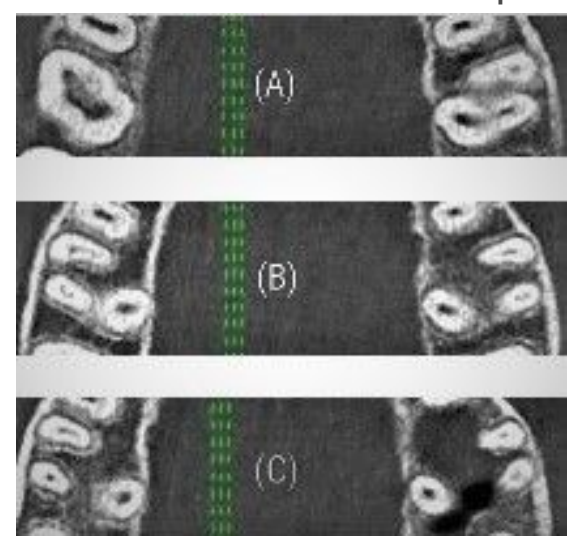

\section{Figure 4}

changed cross-sectional root canal shape for maxillary first molar from ribbon shape in the coronal third to oval in the middle and apical thirds for MB root 

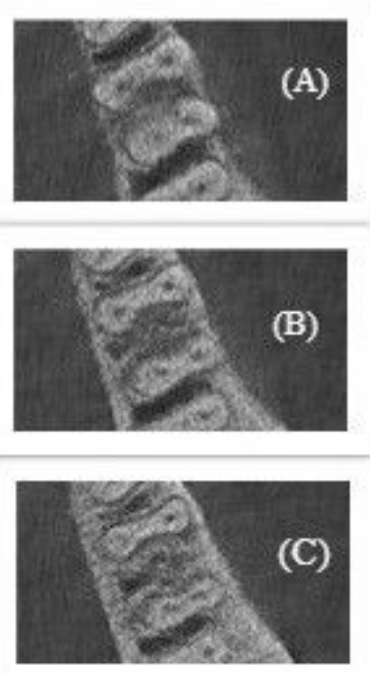

Figure 5

changed cross-sectional root canal shape for mandibular first molar from ribbon shape in the coronal third to ribbon another type in the apical third 